\title{
Proinflammatory functions of vascular endothelial growth factor in alloimmunity
}

\author{
Marlies E.J. Reinders, ${ }^{1,2}$ Masayuki Sho, ${ }^{1,2}$ Atsushi Izawa, ${ }^{1,2}$ Ping Wang, ${ }^{2,3}$ \\ Debabrata Mukhopadhyay, ${ }^{2,3}$ Kerith E. Koss, ${ }^{1}$ Christopher S. Geehan, ${ }^{1}$ \\ Andrew D. Luster, ${ }^{2,4}$ Mohamed H. Sayegh, ${ }^{1,2}$ and David M. Briscoe ${ }^{1,2}$ \\ ${ }^{1}$ Division of Nephrology, Department of Medicine, Children's Hospital, Boston, Massachusetts, USA \\ ${ }^{2}$ Harvard Medical School, Boston, Massachusetts, USA \\ ${ }^{3}$ Department of Pathology, Beth Israel Deaconess Medical Center, Boston, Massachusetts, USA \\ ${ }^{4}$ Division of Rheumatology, Allergy and Immunology, Department of Medicine, Massachusetts General Hospital, \\ Boston, Massachusetts, USA
}

\begin{abstract}
Vascular endothelial growth factor (VEGF), an established angiogenesis factor, is expressed in allografts undergoing rejection, but its function in the rejection process has not been defined. Here, we initially determined that VEGF is functional in the trafficking of human T cells into skin allografts in vivo in the humanized SCID mouse. In vitro, we found that VEGF enhanced endothelial cell expression of the chemokines monocyte chemoattractant protein 1 and IL-8, and in combination with IFN- $\gamma$ synergistically induced endothelial cell production of the potent $\mathrm{T}$ cell chemoattractant IFNinducible protein-10 (IP-10). Treatment of BALB/c $\left(\mathrm{H}-2^{\mathrm{d}}\right)$ recipients of fully MHC-mismatched C57BL/6 $\left(\mathrm{H}-2^{\mathrm{b}}\right)$ donor hearts with anti-VEGF markedly inhibited T cell infiltration of allografts and acute rejection. Anti-VEGF failed to inhibit $\mathrm{T}$ cell activation responses in vivo, but inhibited intragraft expression of several endothelial cell adhesion molecules and chemokines, including IP-10. In addition, whereas VEGF expression was increased, neovascularization was not associated with acute rejection, and treatment of allograft recipients with the angiogenesis inhibitor endostatin failed to inhibit leukocyte infiltration of the grafts. Thus, VEGF appears to be functional in acute allograft rejection via its effects on leukocyte trafficking. Together, these observations provide mechanistic insight into the proinflammatory function of VEGF in immunity.
\end{abstract}

J. Clin. Invest. 112:1655-1665 (2003). doi:10.1172/JCI200317712.

\section{Introduction}

It is well established that leukocyte recruitment into sites of inflammation is associated with angiogenesis, and there is considerable evidence to suggest that angiogenesis and inflammation occur in an interactive and overlapping manner (1-4). Vascular endothelial growth factor (VEGF) is a potent angiogenesis factor that has important roles in both normal physiological as well as pathological vasculogenesis and angiogenesis (5-7). VEGF stimulates endothelial cell proliferation and migration in vitro, and has also been found to reprogram endothelial cell gene expression and to prevent endothelial cells from undergoing apoptosis and senescence $(7,8)$. In addition, VEGF

Received for publication December 30, 2002, and accepted in revised form September 30, 2003.

Address correspondence to: David M. Briscoe, Division of Nephrology, Children's Hospital, 300 Longwood Avenue, Boston, Massachusetts 02115, USA. Phone: (617) 355-6129;

Fax: (617) 232-4315; E-mail: david.briscoe@tch.harvard.edu. Marlies E.J. Reinders and Masayuki Sho contributed equally to this work.

Conflict of interest: The authors have declared that no conflict of interest exists.

Nonstandard abbreviations used: IFN-inducible protein- 10 (IP-10); human umbilical vein endothelial cell (HUVEC); peripheral blood lymphocyte (PBL); mixed lymphocyte reaction (MLR); humanized SCID (huSCID). acts as a proinflammatory cytokine by increasing endothelial cell permeability, by inducing the expression of endothelial cell adhesion molecules, and via its ability to act as a monocyte chemoattractant (9-11). Thus, VEGF is likely a key intermediary between cellmediated immune inflammation and the associated angiogenesis reaction.

VEGF is produced by endothelial cells, macrophages, activated $T$ cells, and a variety of other cell types $(7,12$, 13). It is a heparin-binding, homodimeric glycoprotein with several protein variants resulting from alternative mRNA splicing (5). VEGF binds to three high-affinity tyrosine kinase receptors, Flt-1 (VEGFR-1), KDR (VEGFR-2) (7) and neuropilin (14), expressed almost exclusively by endothelial cells, although Flt- 1 is also expressed by monocytes (15). The major stimulus for VEGF expression is hypoxia (16), but other factors that can upregulate VEGF expression include the degree of cell differentiation; local concentrations of glucose and serum; hormones; prostaglandins; modulators of protein kinase $\mathrm{C}$; nitric oxide; and stimulators of adenylate cyclase $(7,17-20)$. In addition, we recently demonstrated that ligation of CD40 on endothelial cells and monocytes by CD40 ligand (expressed on platelets and activated T cells) is potent for the induction of VEGF, thereby linking immune inflammation with angiogenesis $(12,21)$. 
Little is known about the function of VEGF in alloimmunity. However, VEGF has been observed in human renal and cardiac allografts, and its expression is associated with acute and chronic rejection (22-25). Here, we provide evidence that VEGF functions in the local trafficking of allogeneic leukocytes in vivo and that anti-VEGF is potent in inhibiting the development of acute allograft rejection. These observations provide insight into a general role for VEGF in inflammation and provide compelling evidence that VEGF is of importance in alloimmunity.

\section{Methods}

Reagents. The following antibodies were used for immunohistochemistry in these studies: anti-mouse CD3, -CD4, -CD8, -CD45, and -CD31 (BD Pharmingen, San Diego, California, USA); anti-mouse IFNinducible protein-10 (IP-10) (Antigenix America Inc., Huntington Station, New York, USA); Pan Macrophage Marker (Biosource International, Camarillo, California, USA); anti-human CD3, -CD68, and -vWF (Dako, Carpenteria, California, USA); and anti-human VEGF (Santa Cruz Biotechnology Inc., Santa Cruz, California, USA). Neutralizing monoclonal anti-human VEGF for in vivo studies was a gift from Genentech Inc. (South San Francisco, California, USA) $(26,27)$, and neutralizing monoclonal hamster anti-murine IP-10 for in vivo studies was generated as described (28). The recombinant human cytokines IFN- $\gamma$ and human VEGF $_{165}$ were purchased from R\&D Systems (Minneapolis, Minnesota, USA). Human IgG was purchased from Sigma Aldrich (St. Louis, Missouri, USA), and cyclosporine was purchased from Novartis (Basel, Switzerland). Endostatin (29-31) was a gift from Kashi Javaherian and Judah Folkman (Children's Hospital, Boston, Massachusetts, USA).

Generation of anti-VEGF antiserum. Anti-murine VEGF antiserum was prepared by Maine Biotechnology Services (Portland, Maine, USA) according to the methods of Tilton et al. (32). We used the N-terminal sequence of secreted VEGF, CAPTTEGEQKSHEVIKFMDVYQRSY, coupled with keyhole limpet hemocyanin using the maleimidobenzyl- $N$-hydroxylsuccinimide ester crosslinker. New Zealand White rabbits were then immunized with $500 \mu \mathrm{g}$ of peptide in complete Freund's adjuvant by subcutaneous injection. Rabbits received further immunizations of $250 \mu \mathrm{g}$ peptide in incomplete Freund's adjuvant every 3 weeks. After 6 weeks, anti-VEGF titers were tested by standard ELISA. High titers of anti-VEGF were present in antisera up to a dilution of 1:156,000. Neutralizing activity was assessed in vitro by evaluation of the ability of the antiserum to inhibit murine VEGF-induced proliferation of human umbilical vein endothelial cells (HUVECs) as described (12). The VEGF-neutralizing activity of the antiserum was also assessed in vivo using a modified version of a standard VEGF-induced angiogenesis assay (33). Briefly, Chinese hamster ovary $(\mathrm{CHO})$ cells $\left(1 \times 10^{5}\right.$ cells) expressing VEGF, as described (34), were injected

into the ears of nude mice. The mice received control serum or anti-VEGF antiserum $(0.8 \mathrm{ml})$ intraperitoneally daily starting at day -1 . Marked angiogenesis was evident at days 2-4 in control serum-treated mice, but not in mice that received anti-VEGF antiserum (Figure 1). Overall, using this in vivo assay, there was inhibition of about $80 \%$ of VEGF-induced angiogenesis by the antiserum.

Animals. CB.17 SCID, C57BL/6 (H-2 $\left.{ }^{\mathrm{b}}\right)$, and BALB/c $\left(\mathrm{H}-2^{\mathrm{d}}\right)$ mice were purchased from Taconic (Germantown, New York, USA) and were used at age 6-8 weeks. IP- $10^{-/-}$mice on a pure $129 \mathrm{~Sv} / \mathrm{J}\left(\mathrm{H}-2^{\mathrm{b}}\right)$ background were generated as described (35).

Humanized SCID model. Full-thickness human neonatal foreskin grafts were transplanted onto CB.17 SCID mice as described $(4,36)$ and were allowed to heal for 4-6 weeks. For humanization, peripheral blood lymphocytes (PBLs) were isolated from leukapheresis packs obtained from the Blood Donor Centers at the Children's Hospital and the Dana Farber Cancer Institute (Boston, Massachusetts, USA). All animals received 100 $\mu \mathrm{l}$ of anti-asialo GM1 at 24 hours prior to the transfer of $3 \times 10^{8}$ PBLs by intraperitoneal injection. Antihuman VEGF (Genentech Inc.) was administered on day -2 , at the time of humanization, and every other day $(5 \mathrm{mg} / \mathrm{kg}$ intraperitoneally in $100 \mu \mathrm{l}$ saline) as

$2 d$
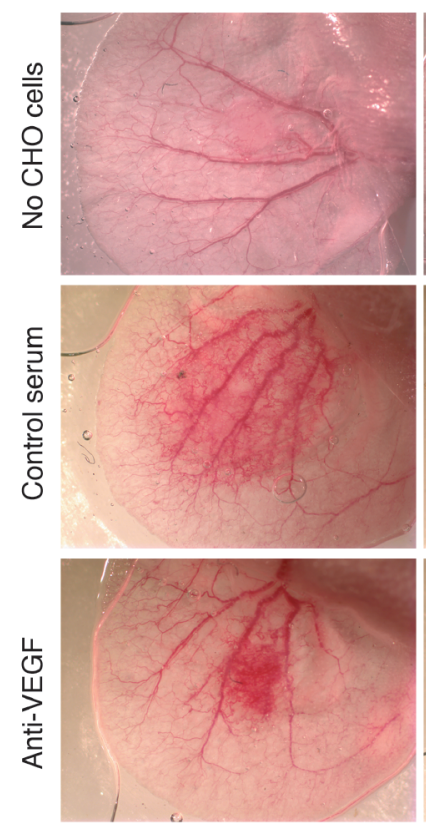

\section{Figure 1}

Anti-VEGF antiserum neutralizes VEGF in vivo. The VEGF-neutralizing activity of antiserum was assessed in vivo using a modified version of a standard VEGF-induced angiogenesis assay. Briefly, $\mathrm{CHO}$ cells $\left(1 \times 10^{5}\right.$ cells $)$ expressing VEGF were injected into the ears of nude mice. The mice received control serum or anti-VEGF antiserum $(0.8 \mathrm{ml})$ intraperitoneally daily starting at day -1 . Marked angiogenesis was evident at days $2-4$ in control serum-treated mice. Overall, using this in vivo assay, there was inhibition of $\sim 80 \%$ of VEGFinduced angiogenesis by the antiserum. 

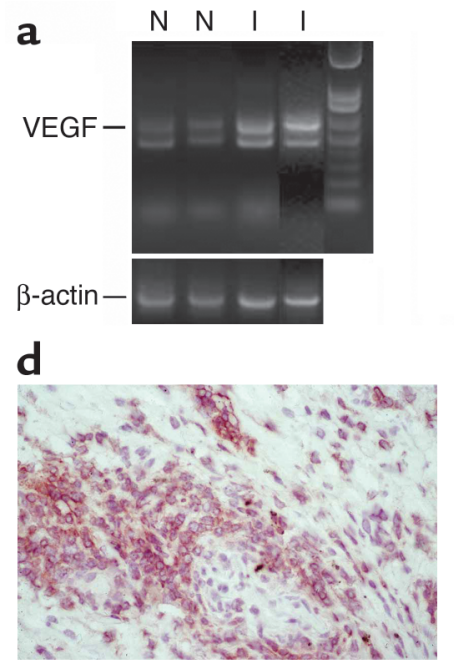

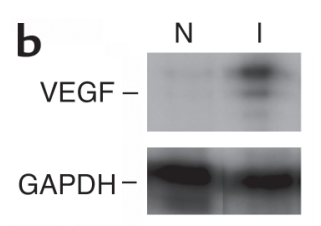

e

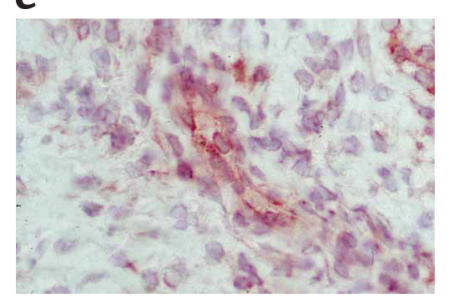

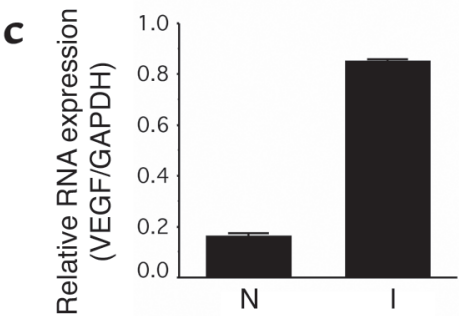

$f$

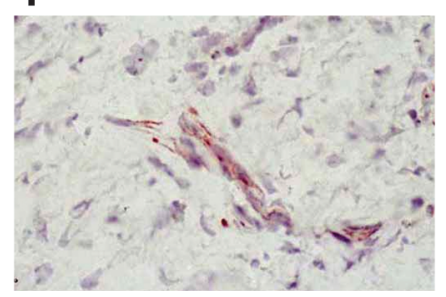

\section{Figure 2}

Expression of VEGF in association with human leukocytic infiltration of skin. SCID mice bearing healed human skin transplants received $3 \times 10^{8}$ human PBLs or saline by intraperitoneal injection. Skin grafts were harvested after 14 days. (a and $\mathbf{b})$ The expression of VEGF mRNA in normal noninfiltrated skins (N; nonhumanized SCID) or in infiltrated skin specimens (I; huSCID) evaluated by RT-PCR (a) and by RNase protection assay $(\mathbf{b})$. (c) The relative expression of VEGF mRNA versus GAPDH evaluated by RNase protection quantified by densitometry. Bar graphs illustrate mean VEGF expression ( \pm 1 SD) for three noninfiltrated $(N)$ or infiltrated (I) skins. (d and e) Expression of VEGF (rose-red) by immunohistochemistry in an infiltrated skin specimen. ( $f$ ) Expression of VEGF (rose-red) in a normal noninfiltrated skin. Note that there is enhanced VEGF expression in association with leukocytic infiltration. Representative of at least ten experiments. Magnification of $\mathbf{d}-\mathbf{f}, \times 400$.

described $(26,27)$. Control mice received $100 \mu$ l saline or human IgG. Animals were sacrificed and skin grafts were harvested after 7 or 14 days. All protocols were in accordance with the Animal Care and Use Committee at Children's Hospital (Boston, Massachusetts, USA).

Immunohistochemistry. Frozen specimens were fixed in acetone, and formalin-fixed specimens were deparaffined. Immunohistochemistry was performed with primary and secondary horseradish peroxidase-conjugated antibodies on frozen sections as described $(4,12)$ and on paraffin-embedded sections using the VectaStain Kit (Vector, Burlinghame, California, USA) and the Tyramide Signal Amplification (TSA) Biotin system (NEN Life Science Products, Boston, Massachusetts, USA) according to the manufacturers' instructions. All specimens were developed in 3-amino ethylcarbazole $(4,12)$ and were counterstained in Gill's hematoxylin.

Grid counting. A standard calibrated grid method was used to quantitatively compare the amount of cellular infiltrate in skin grafts as described (36). Leukocytes were quantitated by counting the immunopositive cells within a calibrated grid at $\times 400$ magnification. Four to six adjacent nonoverlapping fields of each specimen were analyzed by two experimenters blinded to sample identity, and mean counts were calculated.

Murine cardiac transplantation. BALB/c $\left(\mathrm{H}-2^{\mathrm{d}}\right)$ mice were used as recipients of fully MHC-mismatched C57BL/6 $\left(\mathrm{H}-2^{\mathrm{b}}\right)$ or IP-10-/- $\left(\mathrm{H}-2^{\mathrm{b}}\right)$ donor hearts. Vascularized intra-abdominal heterotopic heart transplantation was performed as described (37). Recipients received intraperitoneal injections of (a) $0.8 \mathrm{ml}$ of neutralizing anti-murine VEGF antiserum, or control rab- bit serum, intraperitoneally (38) on days $-1,0,2,4$, and 6; (b) neutralizing anti-IP-10 $(200 \mu \mathrm{g})(39)$ intraperitoneally on days $-1,1,3,5$, and 7 ; or (c) endostatin, 20 $\mathrm{mg} / \mathrm{kg} /$ day (30), subcutaneously from day 0 to day 7 as outlined in Results. Donor hearts were either harvested after 7 days as indicated, or were monitored for the development of rejection. Harvested grafts were divided into three parts and were either "snap frozen" in liquid nitrogen or fixed in formalin for later analysis. Spleen cells obtained from recipients 7 days after transplantation were used in ELISPOT assays as described (40). Briefly, responder cells from controls or antiVEGF-treated recipients were cocultured with stimulator donor spleen cells in a mixed lymphocyte reaction (MLR) for 48 hours. ELISPOT for IFN- $\gamma$ (BD Pharmingen) was performed to assess priming to alloantigen. Cell culture. HUVECs were isolated from umbilical cords and were cultured as previously described (41). Murine endothelial cells were isolated from mouse heart by collagenase digestion and by subsequent sorting using magnetic beads (anti-CD31 and antiICAM-2) as described (42). The purity of endothelial cell cultures was determined by the assessment of baseline cell surface expression of VWF and CD31 and by the cytokine-inducible expression of E-selectin. PBLs or mouse splenocytes were isolated by FicollHypaque gradient centrifugation from blood obtained from healthy volunteers, and MLRs (human, $2 \times 10^{5}$ cells/well; mouse, $4 \times 10^{5}$ cells/well) were performed according to standard procedures (43). Proliferation was assessed after 3 days (mouse) or 5 days (human) by $\left[{ }^{3} \mathrm{H}\right]$ thymidine $(1 \mu \mathrm{Ci} / \mathrm{ml})$ incorporation 
for the last 18 hours of the coculture. Reagents or controls were added to cultures as indicated and ELISA was performed for analysis of IFN- $\gamma$ (Endogen Woburn, Massachusetts), IL-2, or IP-10 (R\&D Systems) in coculture supernatants according to the manufacturers' instructions.

$R T-P C R$ and RNase protection assays. RNA isolated from cultured HUVECs, skin, and heart samples using the Ultraspec RNA Isolation System (Biotecx Laboratories, Houston, Texas, USA) was reverse-transcribed and PCR was performed using standard techniques (12). Sequence-specific primers for PCR were human VEGF (sense primer, 5'-TCACCGCCTCGGCTTGTCACA- $3^{\prime}$; antisense primer, $5^{\prime}$-ATGAACTTTCTGCTGTCTTGG- ${ }^{\prime}$ ), and $\beta$-actin (Stratagene, La Jolla, California, USA) was used as an internal control. PCR reactions were performed under the following conditions: 1 cycle at $94^{\circ} \mathrm{C}$ for 5 minutes followed by 35 cycles at $94^{\circ} \mathrm{C}$ for 1 minute, $60^{\circ} \mathrm{C}$ for 1 minute, and $72^{\circ} \mathrm{C}$ for 1 minute. The last cycle was extended to 7 minutes at $72^{\circ} \mathrm{C}$. The amplified products were resolved by electrophoresis in an ethidium bromide-stained $1.5 \%$ agarose gel.

RNase protection assays were performed using the RiboQuant multiprobe template system (BD Pharmingen) according to the manufacturer's instructions (12). Relative signals were detected by autoradiography with Kodak MR film, and expression was quantified by densitometry by means of an AlphaImager 2000 system (Alpha Innotech, San Leandro, California, USA). For quantification, signals were standardized to the internal housekeeping gene GAPDH.
Statistical analysis. Data were compared by nonparametric analysis using the Log Rank Test for allograft survival studies, and the Mann-Whitney test was used for immunohistological studies. $P$ values less than 0.05 were considered statistically significant.

\section{Results}

Function of VEGF in allogeneic human leukocyte recruitment. We first used the huSCID mouse to determine the effect of VEGF on leukocyte trafficking into human skin. This model is unique, as circulating human leukocytes in the huSCID mouse selectively interact with human endothelial cells in the skin allograft $(4,36,44)$, allowing for the analysis of molecules involved in endothelial cell-dependent mechanisms of human leukocyte trafficking. In our model, human foreskin is transplanted onto SCID mice and is allowed to heal for 4-6 weeks. After adoptive transfer of human PBLs into the mouse by intraperitoneal injection, $\mathrm{CD}^{+}$and $\mathrm{CD} 8^{+}$ $\mathrm{T}$ cells as well as $\mathrm{CD} 68^{+}$monocytes/macrophages infiltrate the human skin over 7-14 days (4). As previously described (36), healed human skin in the huSCID mouse is vascularized by both human and mouse vasculature, but human alloreactive leukocytes selectively interact and mediate vasculitis of only the human vessels. Thus, skin allografts do not slough in this model, as the murine vasculature maintains blood flow and integrity of the skin despite marked leukocyte infiltration and marked vasculitis of the human vessels $(4,44)$.

We initially evaluated the expression of VEGF in noninfiltrated and infiltrated human skin specimens from nonhumanized or huSCID mice, respectively, and
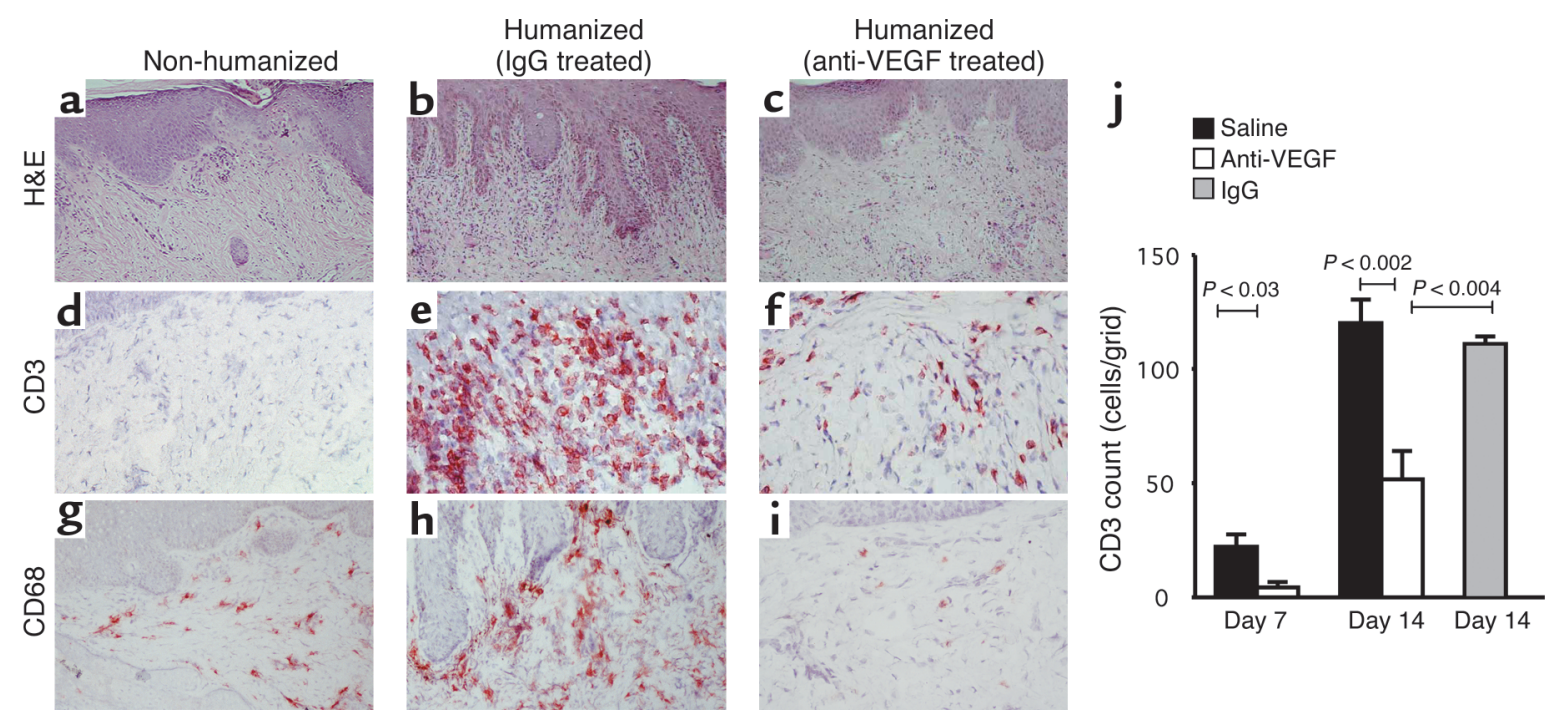

Figure 3

Function of VEGF in human leukocyte recruitment. Saline, IgG, or anti-human VEGF were received by huSCID mice bearing human skin transplants. (a-i) Skin grafts were harvested 14 days after humanization and infiltrates were identified by H\&E staining (a-c), by immunostaining with anti-human CD3 (d-f), and by immunostaining with anti-human CD68 (g-i). Treatment of huSCID mice with anti-human VEGF inhibited both $\mathrm{CD} 3^{+} \mathrm{T}$ cell $(\mathbf{f})$ and $\mathrm{CD} 68^{+}$monocyte macrophage (i) infiltration of skin. (j) Quantitative assessment of CD3 ${ }^{+} \mathrm{T}$ cell infiltrates was performed by calibrated grid counting at a magnification of $\times 400$ in skin specimens harvested at either day 7 or day 14 following humanization. The mean CD3 count per calibrated field is illustrated in skins harvested from animals treated with saline $(n=7$ at day $7 ; n=10$ at day 14$)$, anti-human $\operatorname{VEGF~(~} n=5$ at day $7 ; n=10$ at day 14$)$, or control $\operatorname{IgG}(n=4$ at day 14$)$. 

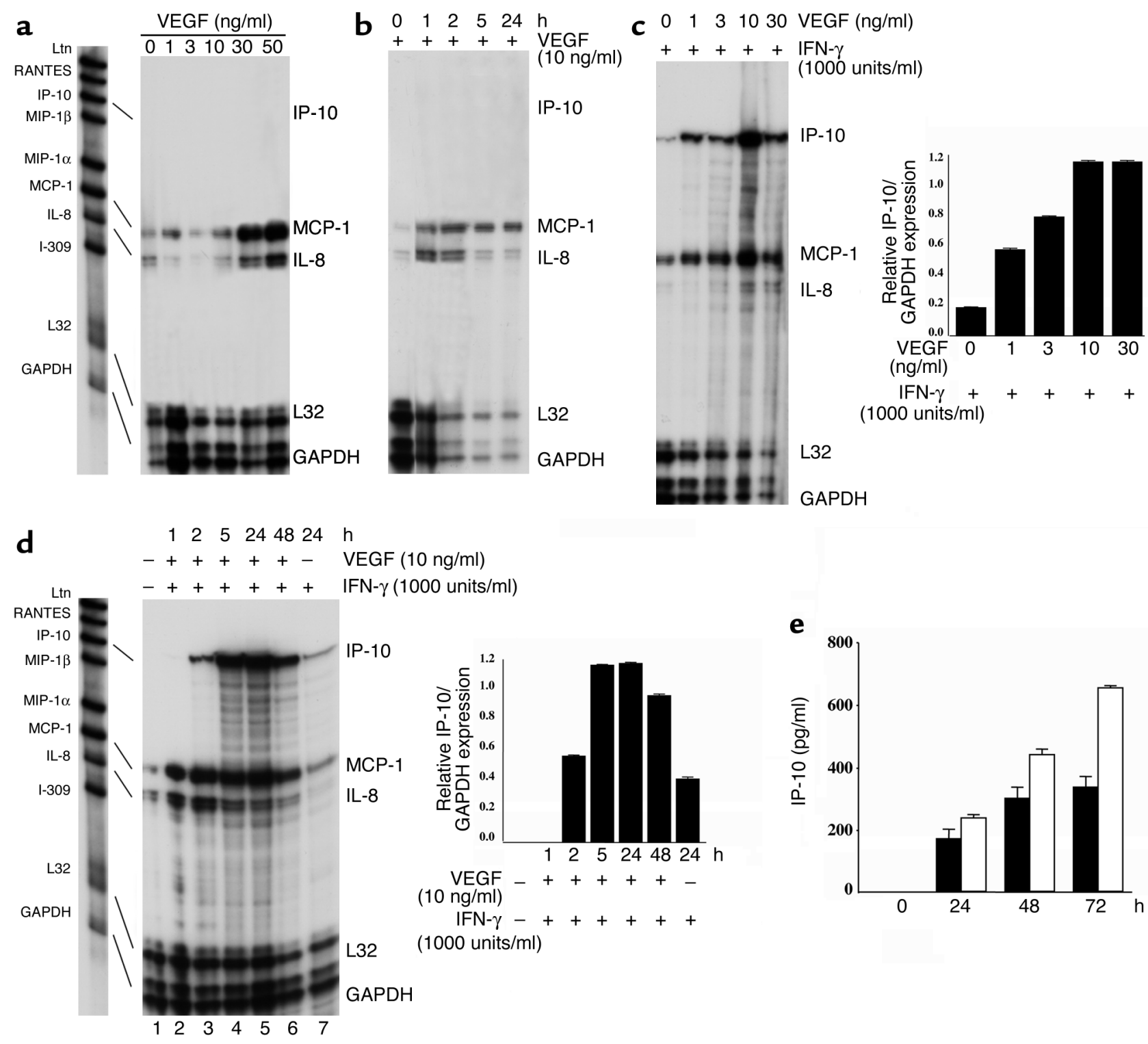

Figure 4

Effect of VEGF on endothelial cell chemokine expression. (a-d) Confluent cultures of human endothelial cells were treated for 4 hours (a and $\mathbf{c}$ ) or as a time course ( $\mathbf{b}$ and $\mathbf{d}$ ) with VEGF alone or VEGF in combination with IFN- $\gamma$ as indicated. Total RNA was harvested from endothelial cells and the expression of chemokines was analyzed by RNase protection assay. Concentration- (a) and time-dependent (b) effects of VEGF on chemokine expression. (c and d) Effect of IFN- $\gamma$ alone or in combination with VEGF on chemokine expression. Note that treatment with IFN- $\gamma$ alone resulted in IP-10 expression ( $\mathbf{c}$, and $\mathbf{d}$ lane 7 ), and a combination of IFN- $\gamma$ with VEGF resulted in a synergistic induction of IP-10 (c, and d lanes 2-6). Bar graphs to the right of each blot represent the quantitative analysis of IP-10 mRNA expression in three representative RNase protection assays as illustrated in $\mathbf{c}$ and $\mathbf{d}$. (e) The production of IP-10 by ELISA in culture supernatants of endothelial cells treated with IFN- $\gamma(1,000 \mathrm{U} / \mathrm{ml}$; black bars) or with VEGF $(10 \mathrm{ng} / \mathrm{ml})$ and IFN- $\gamma(1,000 \mathrm{U} / \mathrm{ml})$ (white bars) for different times as indicated. Representative of three similar experiments performed in triplicate (mean $\pm 1 \mathrm{SD}$ ).

found enhanced VEGF mRNA and protein expression in association with infiltrates (Figure 2). By immunohistochemistry, VEGF protein was expressed by both inflammatory infiltrates and by vascular endothelial cells (Figure 2, $d$ and e). In contrast, in skin specimens without infiltrates, VEGF was only found on keratinocytes and endothelial cells with minimal expression overall (Figure 2f). We treated huSCID mice with a neutralizing antihuman VEGF, human IgG, or saline. Consistent with its known function as a monocyte chemo- attractant (11) anti-VEGF had a significant inhibitory effect on the recruitment of $\mathrm{CD} 68^{+}$monocytes/ macrophages (Figure 3). Few $\mathrm{CD} 68^{+}$cells were evident in skins harvested from animals treated with antiVEGF (Figure 3i). Moreover, we unexpectedly found that anti-VEGF was most potent at inhibiting $\mathrm{CD}^{+} \mathrm{T}$ cell trafficking into human skin (Figure 3, d-f). By quantitative grid counting analysis, there was a statistically significant decrease in $\mathrm{CD}^{+} \mathrm{T}$ cell infiltrates in anti-VEGF-treated huSCID animals both at day 7 and 
at day 14 (Figure 3j). Therefore, VEGF is functional for peripheral recruitment and for the trafficking of human allogeneic lymphocytes and monocytes in vivo. We also assessed the effect of anti-VEGF on the angiogenesis reaction, which we have previously reported to be associated with mononuclear cell infiltration in this model (4). Our findings were that anti-VEGF markedly inhibited angiogenesis (data not shown), which is consistent with the interpretation that locally expressed VEGF is also of functional importance in leukocyte-associated angiogenesis.

In vitro analysis of VEGF-dependent chemokine production in endothelial cells. The function of VEGF as a monocyte chemoattractant is established in vitro (11). However, our finding that VEGF promotes $T$ cell recruitment has not been previously reported in vitro or in vivo, to our knowledge. To study the mechanism of function of VEGF on T cell recruitment, we next assessed the effect of VEGF on human endothelial cell activation in vitro. Treatment of confluent cultures of endothelial cells with increasing concentrations of VEGF resulted in a dose-dependent increase in the expression of the endothelial cell adhesion molecules E-selectin, ICAM-1, and VCAM-1 (not shown, and as reported by others [refs. 9, 10]). In addition, after treatment with VEGF, we found that the endothelial cell expression of the chemokines monocyte chemoattractant protein 1 (MCP-1) and interleukin-8 (IL-8) was also increased (Figure 4a). MCP-1 peaked in expression between 1 and 5 hours following treatment, and expression persisted for up to 24 hours (Figure 4b). In contrast, IL-8 peaked in expression at approximately 2 hours following treatment, and decreased in expression by 24 hours. But there was no increase in the expression of the $\mathrm{T}$ cell-chemoattractant chemokines lymphotactin, RANTES, IP-10 (Figure 4), or Mig (not shown) after VEGF treatment.

Since IFN- $\gamma$-induced chemokines play a major role in the local recruitment of allogeneic lymphocytes, we also determined an effect of VEGF on IFN- $\gamma$-mediated activation of the potent $\mathrm{T}$ cell-chemoattractant chemokines IP-10 and Mig. We treated endothelial cells with IFN- $\gamma$ and found induced expression of IP-10 and Mig, as reported $(45,46)$. Moreover, we observed that a combination of VEGF with IFN- $\gamma$ resulted in a synergistic induction of endothelial cell IP-10 mRNA and
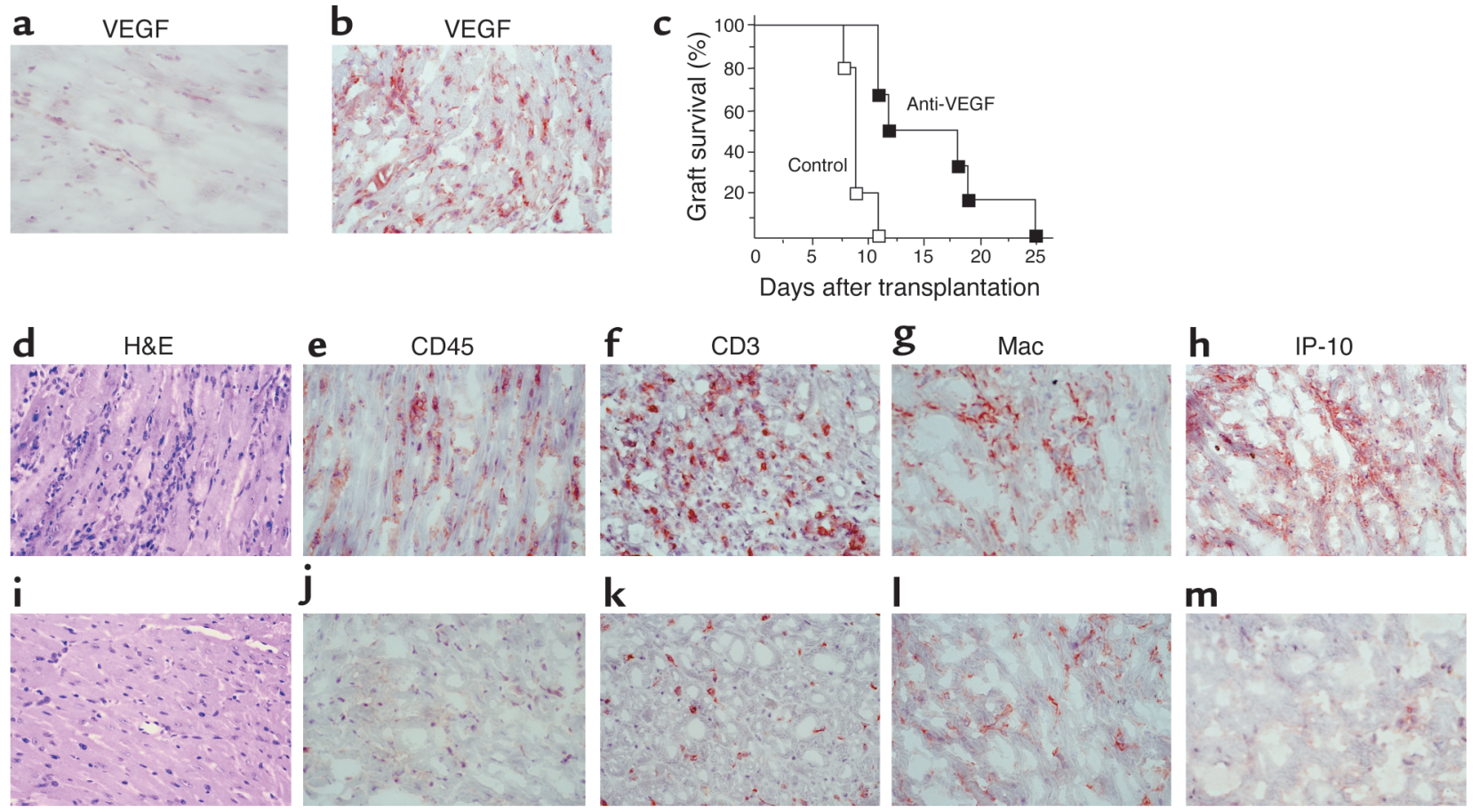

\section{Figure 5}

Blockade of VEGF in a fully MHC-mismatched murine model of acute cardiac allograft rejection. Fully MHC-mismatched C57BL/6 $\left(\mathrm{H}-2^{\mathrm{b}}\right)$ donor hearts were transplanted into BALB/c $\left(\mathrm{H}-2^{\mathrm{d}}\right)$ mice as recipients. Untreated recipients develop marked leukocytic infiltrates and rejection by day 7. (a and $\mathbf{b}$ ) Immunohistochemical analysis of VEGF in a normal nontransplanted heart (a) and in a rejecting allograft at day 7 (b), showing intense VEGF expression in association with allograft rejection. (c) Graft survival curves for recipients treated with anti-VEGF antiserum (filled squares; $n=6$ ) or normal rabbit serum as a control (open squares; $n=5$ ). Anti-VEGF-treated recipients show prolonged heart allograft survival $(P<0.001)$. ( $\mathbf{d}-\mathbf{m})$ Histological analysis of cardiac allografts harvested at day 7 after transplantation from rejecting control serum-treated animals ( $\mathbf{d}-\mathbf{h})$ or from animals treated with anti-VEGF $(\mathbf{i}-\mathbf{m})$. Control serum-treated animals had evidence of severe cellular rejection with extensive mononuclear cell infiltration (d), including $\mathrm{CD}^{+} 5^{+},(\mathbf{e}) \mathrm{CD}^{+}(\mathbf{f})$, and macrophage $(\mathrm{Mac})(\mathbf{g})$ infiltrates. In contrast, recipients treated with anti-VEGF had minimal infiltrates and no evidence of vasculitis (i-I). (h and $\mathbf{m})$ IP-10 protein expression was diffuse and intense within allografts in association with rejection (h) but was of low intensity and sparse in anti-VEGF-treated recipients $(\mathbf{m})$. Representative immunostaining of five animals from each group; magnification, $\times 400$. 

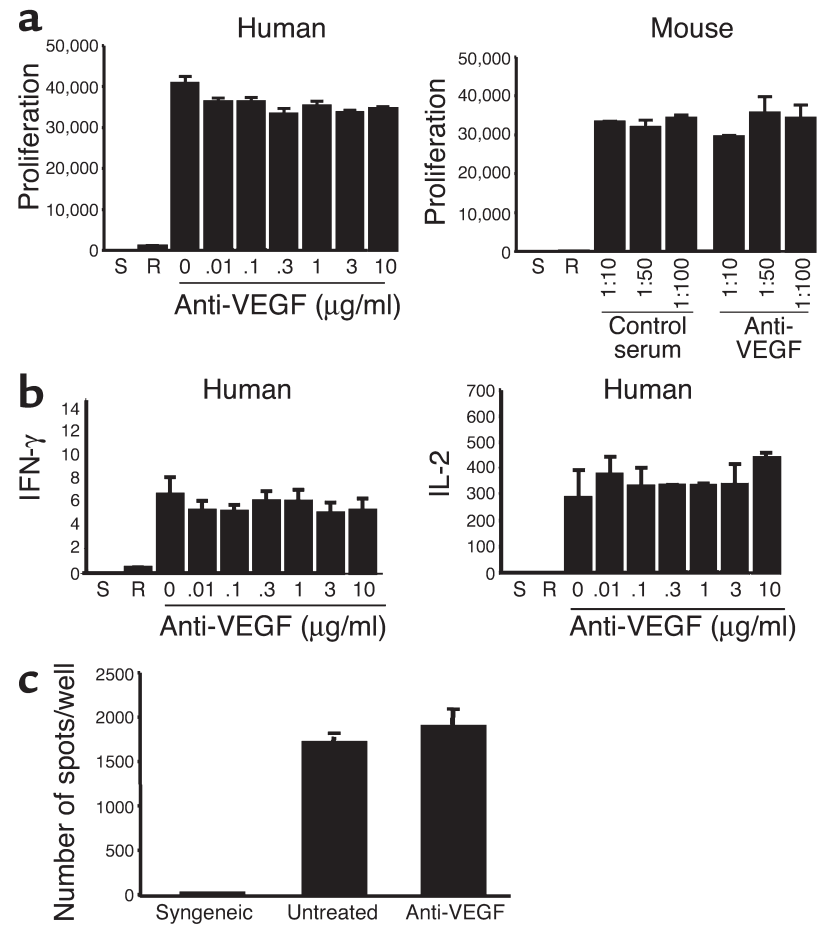

protein expression, but not Mig expression (Figure 4, $\mathrm{c}-\mathrm{e}$, and not shown). In addition, we observed that IFN- $\gamma$ inhibited the expression of IL-8, and that combinations of VEGF and IFN- $\gamma$ restored IL-8 expression (Figure 4, $c$ and d). Thus, VEGF may promote human allogeneic lymphocyte trafficking in vivo via regulation of endothelial cell production of chemokines including the potent $\mathrm{T}$ cell chemokine IP-10.

Blockade of VEGF in a fully MHC-mismatched murine model of acute cardiac allograft rejection. Our results also raise the possibility that VEGF is of importance in allo-

\section{Figure 6}

Function of VEGF in alloimmune $T$ cell activation and allograft rejection. (a) Anti-human VEGF or anti-murine VEGF antiserum was added into the human or the mouse MLR, respectively. Proliferation was assessed by $\left[{ }^{3} \mathrm{H}\right]$ thymidine incorporation for the last 18 hours of coculture. (b) The production of IFN- $\gamma$ and IL- 2 was assessed by ELISA in coculture supernatants from a human MLR. As illustrated, blockade of VEGF had no effect on proliferation or cytokine production in the MLR. Bars indicate the mean \pm 1 SD for triplicate wells. Data are representative of three experiments with similar results. $S$, stimulators alone; R, responders alone. (c) Frequency of IFN- $\gamma$-producing cells in murine recipients of cardiac transplants as assessed by ELISPOT. Illustrated is the production of IFN- $\gamma$ from a syngeneic, an untreated, and an anti-VEGF-treated animal. Representative of three such experiments performed in triplicate.

graft rejection. Allograft rejection is a complex multicellular process that is critically dependent upon $\mathrm{T}$ cell recognition of alloantigen processed and presented to $\mathrm{T}$ cells by either donor or recipient antigen-presenting cells (47). The subsequent recruitment of activated $T$ cells and effector cells into an allograft has been shown to be mediated in part by locally expressed leukocyteendothelial adhesion molecules (48) and chemokines (49). We used a physiological in vivo model of acute allograft rejection in which fully MHC-mismatched $\mathrm{C} 57 \mathrm{BL} / 6\left(\mathrm{H}-2^{\mathrm{b}}\right)$ donor hearts were transplanted into $\mathrm{BALB} / \mathrm{c}\left(\mathrm{H}-2^{\mathrm{d}}\right)$ recipients. Similar to our findings in the huSCID mouse (above), VEGF was expressed in association with graft infiltrates and acute rejection (Figure 5 , a and b). Administration of our neutralizing antiVEGF antiserum resulted in a significant prolongation of allograft survival up to 25 days after transplant versus 11 days in control serum-treated animals (Figure $5 c, P<0.01)$. Severe cellular rejection with extensive mononuclear cell infiltration and myocyte necrosis was evident in sections of rejecting grafts at day 7 in recipi-

\section{Figure 7}

Function of angiogenesis in acute rejection. Fully MHC-mismatched C57BL/6 $\left(\mathrm{H}-2^{\mathrm{b}}\right)$ donor hearts were transplanted into $\mathrm{BALB} / \mathrm{c}\left(\mathrm{H}-2^{\mathrm{d}}\right)$ mice, and recipients were treated with control Ig, anti-VEGF, or endostatin, as described in Methods. (a) Immunohistochemical analysis of CD31 in isografts or allografts harvested at day 7 from animals treated with control Ig or anti-VEGF. (b) H\&E staining of allografts harvested from untreated or endostatin-treated animals at day 7 showing notable infiltrates in both untreated and treated grafts at low magnification (left; magnification, $\times 200$ ) and at high magnification (right; magnification, $\times 400)$. Representative of eight animals. (c) Immunostaining for CD3-expressing $T$ cells in a representative allograft from an endostatin-treated animal. (d) Graft survival curves for untreated recipients (dotted line; $n=10$ ), or recipients treated with endostatin (solid line; $n=8$ ). Note that the endostatin used in these studies inhibited angiogenesis in control animals with tumors (not shown and as described in ref. 30), but only minimally prolonged graft survival in three of eight animals.

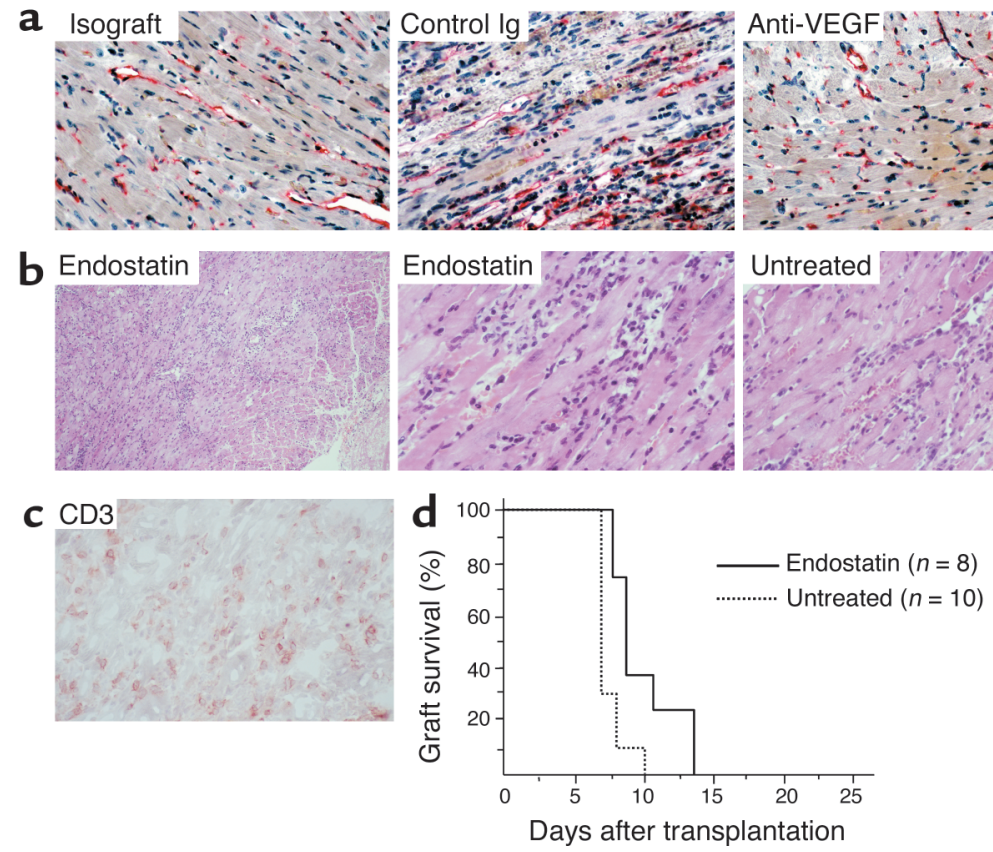


ents treated with control rabbit serum (Figure 5, d-g). In contrast, we observed only a mild to moderate infiltrate, reduced numbers of $\mathrm{CD}^{+} \mathrm{T}$ cells and monocytes/macrophages, less myocyte damage, and minimal vasculitis in allografts from recipients treated with anti-VEGF antiserum (Figure 5, i-1). Moreover, the $\mathrm{T}$ cell chemoattractant IP-10 was observed in abundance on multiple cell types in rejecting grafts (Figure 5h), but there was minimal expression in grafts harvested from animals treated with anti-VEGF (Figure $5 \mathrm{~m}$ ). Therefore, the intense expression of VEGF in allografts in vivo is of mechanistic significance in promoting the development of rejection.

Mechanism of function of VEGF in allograft rejection in vivo. The effect of anti-VEGF on leukocyte trafficking and allograft rejection in our in vivo studies could be explained by an effect of VEGF on $T$ cell activation responses. However, the addition of our antibodies against VEGF to cocultures in human or mouse MLRs failed to inhibit $T$ cell activation responses (Figure 6, $a$ and $b$ ). Also, the in vivo priming of $T$ cells to alloantigen as manifested by ELISPOT analysis of IFN- $\gamma$ in murine recipients of allografts (above) was unaltered by anti-VEGF treatment (Figure $6 \mathrm{c}$ ). Thus, VEGF does not function in alloimmune $\mathrm{T}$ cell activation in vitro or in vivo.

We next assessed whether the intense intragraft expression of VEGF in acute rejection could mediate leukocyte recruitment in part via neovascularization. By immunohistochemistry, we found that endothelial CD31 was expressed diffusely on large vessels as well as microvessels throughout all grafts examined (Figure 7a). Moreover, the staining pattern of CD31 as well as the vascularization of isografts was very similar to that found in anti-VEGF-treated grafts. In contrast, we found fewer CD31-expressing vessels in control Ig-treated rejecting grafts; and some focal areas of rejecting grafts were devoid of any vascular staining (Figure $7 \mathrm{a}$, and not shown). To assess the possibility of a role for angiogenesis in acute rejection, we also treated animals with endostatin, a known endothelial cell-specific inhibitor of angiogenesis (29) (Figure 7, b-d). Our findings were that endostatin had a minimal effect on allograft survival, prolonging survival in three of eight animals; and failed to have any effect on leukocyte trafficking into the graft (Figure 7, b-d). Because the effect of endostatin was so markedly different than that following treatment with anti-VEGF (Figure 5), we interpret these data as suggesting that VEGF mediates leukocyte trafficking into an allograft independent of an effect on angiogenesis.

To further define the role of VEGF in $\mathrm{T}$ cell recruitment into cardiac allografts, we examined the effect of VEGF in primary cultures murine myocardial endothelial cells in vitro. In contrast to our findings in human endothelial cells, we found that VEGF alone induced the expression of IP-10 in murine endothelial cells (Figure 8a). Thus, it is possible that VEGF may regulate $\mathrm{T}$ cell trafficking primarily via IP-10-dependent mechanisms. Indeed, local intragraft endothelial cell expression of IP-10 has been previously reported to be of critical importance in the recruitment of $\mathrm{T}$ cells into allografts in rejection (39). Transplanted animals were next treated with neutralizing anti-IP-10 alone or in combination with anti-VEGF (Figure 8b). Our findings were that anti-IP-10 alone prolonged graft survival, and that combined treatment with anti-IP-10 and antiVEGF significantly prolonged allograft survival versus treatment with anti-IP-10 alone or anti-VEGF alone (Figure 8b, $P<0.005$ and $P<0.03$, respectively). This is suggestive that a major effect of anti-VEGF in vivo is independent of IP-10. To further confirm this interpretation, we also transplanted allografts from IP-10-/donors into wild-type mice and again found that antiVEGF prolonged survival in the absence of local IP-10 production (Figure $8 c, P<0.04$ ).
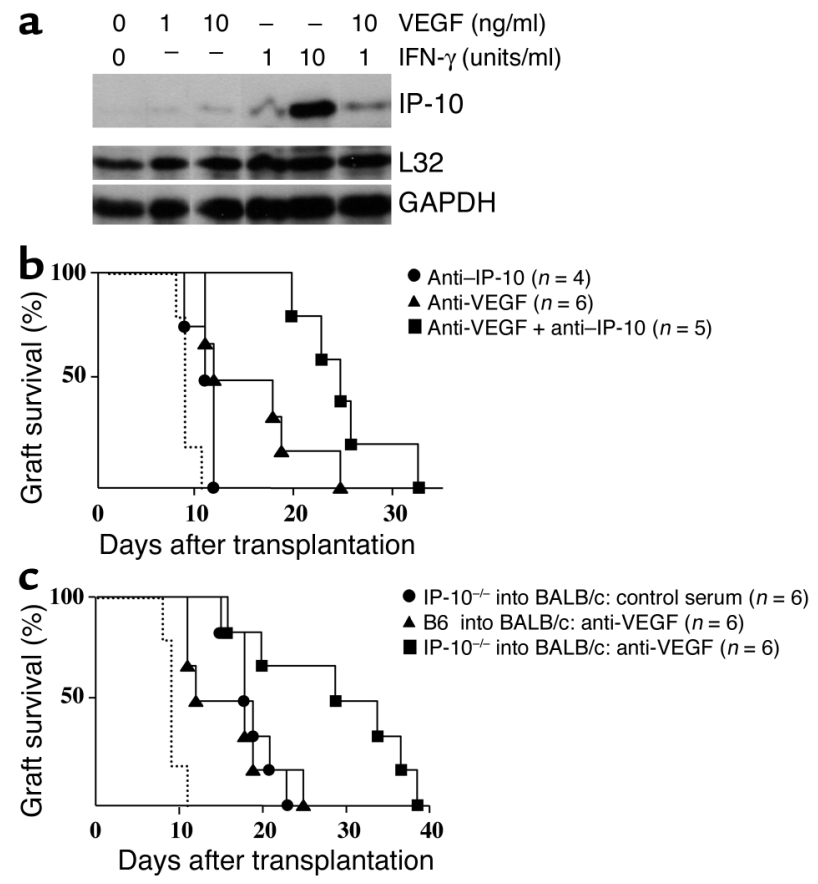

\section{Figure 8}

Function of VEGF-dependent regulation of IP-10 in allograft rejection. (a) Confluent cultures of murine myocardial endothelial cells were treated for 4 hours with recombinant murine VEGF or IFN- $\gamma$ alone or VEGF in combination with IFN- $\gamma$ as indicated. Total RNA was harvested from endothelial cells and the expression of IP-10 was analyzed by RNase protection assay. ( $\mathbf{b}$ and $\mathbf{c}$ ) The ability of VEGF to mediate IP-10-dependent trafficking and rejection was evaluated using antiVEGF and anti-IP-10 in fully MHC-mismatched C57BL/6 $\left(\mathrm{H}-2^{\mathrm{b}}\right)$ or IP-10 $-/-\left(\mathrm{H}-2^{\mathrm{b}}\right)$ donor hearts transplanted into BALB/c $\left(\mathrm{H}-2^{\mathrm{d}}\right)$ mice. Recipients of wild-type grafts were treated with anti-VEGF alone, or with anti-VEGF in combination with anti-IP-10. Recipients of IP-10 donor grafts were treated with anti-VEGF. Both anti-IP-10 and antiVEGF were administered according to the schedule outlined in Methods. As illustrated in $\mathbf{b}$, we found that addition of anti-VEGF with anti-IP-10 significantly prolonged allograft survival in wild-type combinations $(P<0.005)$; and in c, anti-VEGF prolonged survival in mice that received IP-10-/- donor hearts $(P<0.04)$. The survival of control untreated wild-type grafts are illustrated by the dotted line. 

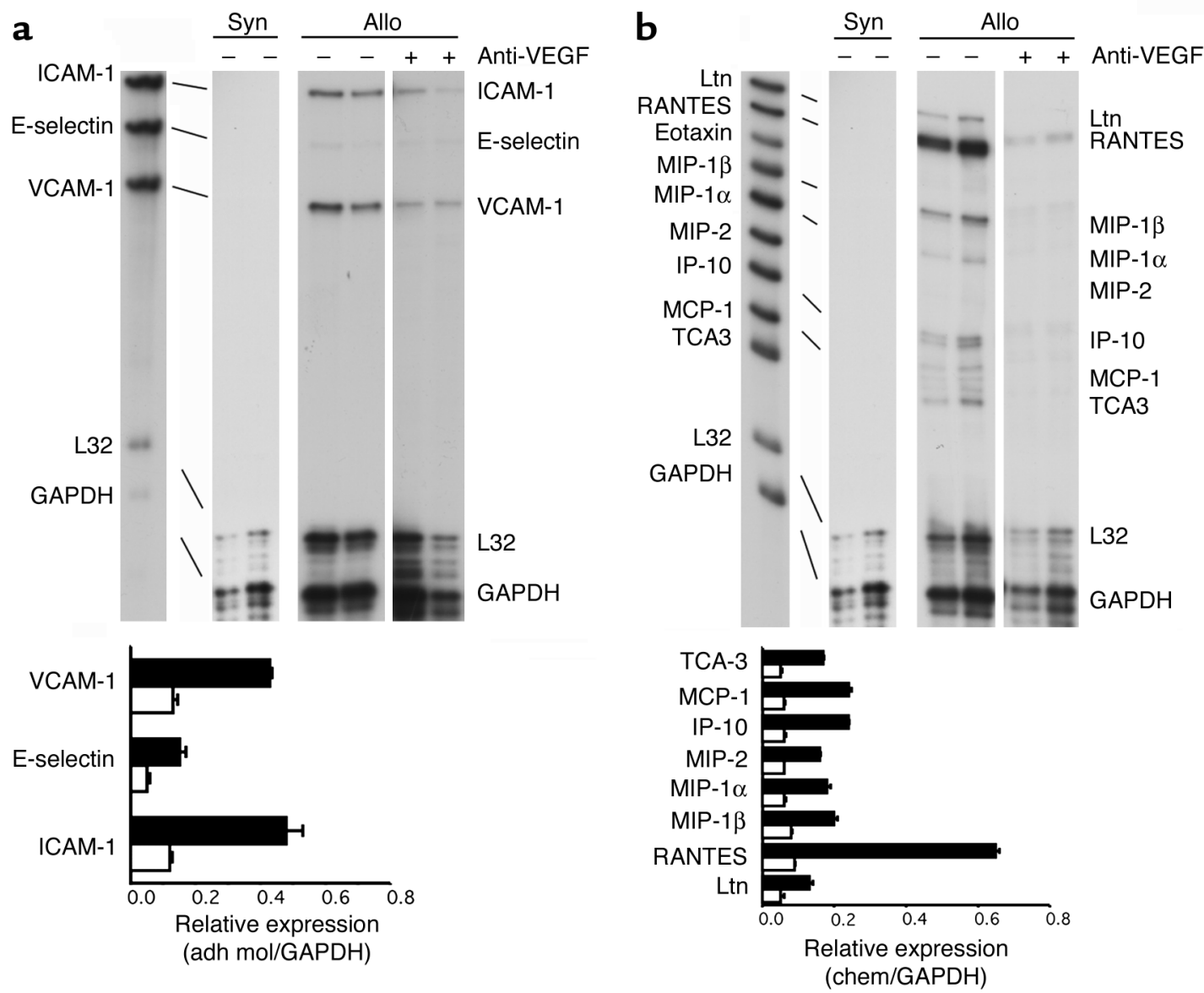

Figure 9

Effect of Anti-VEGF on the intragraft expression of adhesion molecules and chemokines. Analysis of endothelial cell adhesion molecule expression (a) and chemokine expression (b) in cardiac syngeneic grafts (Syn) or allografts (Allo) at day 7. Recipients received either control normal rabbit serum (-) or anti-VEGF antiserum $(+)$. The bar graphs represent quantitative analysis of mRNA expression as the relative expression of adhesion molecules (adh mol) or chemokines (chem) compared with the expression of GAPDH. Mean expression ( \pm 1 SD) for three animals treated with normal rabbit serum (black bars) or anti-VEGF antiserum (white bars) is shown.

Lastly, we examined adhesion molecule and chemokine expression in vivo in cardiac allografts harvested on day 7 from control or anti-VEGF-treated wild-type mice. By RNase protection assay, we found a significant decrease in the expression of E-selectin, ICAM-1, and VCAM-1 in anti-VEGF-treated animals compared with that of controls (Figure 9a). In addition, anti-VEGF markedly inhibited the intragraft expression of several $\mathrm{T}$ cell-chemoattractant chemokines (including lymphotactin, RANTES, and IP-10) as well as the monocyte chemoattractant MCP-1 (Figure 9b). Thus, blockade of VEGF in vivo inhibits the local expression of several chemokines that are not directly regulated by VEGF. We interpret our findings as suggesting that VEGF is of importance in allograft rejection at early times after transplantation and prior to the induced expression and function of $\mathrm{T}$ cell-derived chemokines. Intragraft VEGF expression appears to promote early $\mathrm{T}$ cell and monocyte trafficking, and subsequent activation events result in additional VEGF expression as well as the expression of chemokines (including IP-10); both of these effects are additive in promoting rejection.

\section{Discussion}

VEGF is a most potent and critical mediator of physiological as well as pathological angiogenesis. Its expression and function have been reported in several chronic inflammatory processes; however, its mechanism of function in immunity has been unclear. Recent reports have defined the angiogenesis reaction mediated by VEGF to be proinflammatory in chronic inflammation (7). Here, we provide evidence that VEGF promotes endothelial cell chemokine production in vitro and in vivo and functions in the recruitment of monocytes and T cells into allografts. VEGF is thus an important proinflammatory cytokine in transplant rejection.

The expression of VEGF has been reported to be associated with allograft rejection (especially chronic rejection) in both experimental models and following human transplantation $(22,24,25)$. In addition, it has been reported that transplant recipients with polymorphisms in the VEGF gene, encoding high VEGF production, are at increased risk for the development of acute renal allograft rejection (23). Here, we extend upon those observations and demonstrate that intra- 
graft VEGF has a biological effect in vivo in promoting rejection, as leukocyte infiltration is inhibited following treatment with neutralizing anti-VEGF. Moreover, we demonstrate that induced intragraft VEGF is unlikely to be functional for the development of angiogenesis, as neovascularization is not a component of the rejection process. Rather, we show that the mechanism of function of VEGF appears to involve its ability to mediate intragraft leukocyte trafficking.

It is well established that the process of recruitment involves coordinate interactions among adhesion molecules and chemokines $(3,49)$. Multiple individual molecules have been shown to be functional in the process of rejection (49-52), suggesting that there is some redundancy in the function of adhesion molecules and chemokines in vivo. It is known that VEGF induces the expression of adhesion molecules in human endothelial cells $(9,10)$, and two recent reports have pointed to an effect of VEGF on chemokine production $(53,54)$. Here, we extend upon those observations and show that VEGF regulates IP-10, MCP-1, and IL-8, as well as the endothelial cell adhesion molecules E-selectin, ICAM-1, and VCAM-1, in vitro and in vivo. All of these molecules are expressed in association with rejection, and blockade of several molecules or their ligands individually (e.g., IP-10, MCP-1, ICAM-1, and VCAM-1) (49-52) has been shown to prolong allograft survival in murine models. Our data in this study imply that the ability of VEGF to regulate several of these molecules is the basis for its function in leukocyte trafficking. However, we have not fully addressed this complex question at an individual molecular level, and thus this interpretation will require further study. Nevertheless, of all chemokine-chemokine receptor interactions studied to date, the most profound effects on graft survival are seen when the $T$ cell chemoattractant IP-10 or its ligand CXCR3 are targeted $(39,50,55)$. We found that VEGF-dependent $\mathrm{T}$ cell trafficking and rejection in vivo was not restricted to the function of IP-10. Our results therefore provide a framework for an analysis of the role of VEGF in the expression and function of individual chemokines and adhesion molecules in leukocyte trafficking, in rejection, and in other cellmediated immune inflammatory diseases $(7,38)$.

Another interpretation of our findings is that the major proinflammatory function of VEGF is in the initiation of the inflammatory cascade, rather than in subsequent events resulting from $\mathrm{T}$ cell-mediated activation responses. Consistent with this possibility, it is important to note that hypoxia is the major stimulus for VEGF expression (16). This suggests that VEGF will be produced locally within allografts immediately following transplantation. Additional insults, including platelet and leukocyte recruitment into the graft, will further facilitate the expression of local VEGF (12) as well as other cytokines and chemokines (56) that are of importance in the rejection process $(47,49,57)$. Here, we have provided evidence that early VEGF expression promotes $\mathrm{T}$ cell and monocyte recruitment. We suggest that the subsequent induced expression of chemokines (e.g., IP-10) and VEGF are additive in promoting the development of rejection. As it is well established that early insults to allografts (such as prolonged ischemia) have long-term consequences (58), dysregulation of VEGF at early times following transplantation may have beneficial effects in promoting graft survival. Indeed, in support of this possibility, it has been noted that early (but not late) blockade of VEGF can limit the development of chronic arthritis (38).

In summary, our results provide compelling evidence that VEGF is a proinflammatory cytokine in allograft rejection. In addition, they provide insight into the role of VEGF in cell-mediated inflammatory reactions in immunity. We suggest that VEGF warrants consideration as a target for future therapeutic intervention following transplantation.

\section{Acknowledgments}

This work was supported by NIH grants AI46756 to D.M. Briscoe and CA069212 to A.D. Luster. The authors wish to thank Don Senger, Beth Israel Deaconess Medical Center, for help with the generation of anti-VEGF antiserum; Kashi Javaherian and Judah Folkman for the gift of endostatin; and Stuart Robertson, Evelyn Flynn, and William Wong for assistance with these studies. We also thank the maternity staff at South Shore Hospital for the supply of umbilical cords used for the generation of endothelial cells.

1. Sidky, Y.A., and Auerbach, R. 1975. Lymphocyte-induced angiogenesis: a quantitative and sensitive assay of the graft-vs.-host reaction. J. Exp. Med. 141:1084-1100

2. Auerbach, R., and Sidky, Y.A. 1979. Nature of the stimulus leading to lymphocyte-induced angiogenesis. J. Immunol. 123:751-754.

3. Cotran, R.S. 1994. Inflammation and repair. In Pathologic basis of disease. R.S. Cotran, V. Kumar, and S.L. Robbins, editors. WB Saunders, Philadelphia, USA. 51-92.

4. Moulton, K.S., et al. 1999. Angiogenesis in the huPBL-SCID model of human transplant rejection. Transplantation. 67:1626-1631.

5. Leung, D.W., Cachianes, G., Kuang, W.J., Goeddel, D.V., and Ferrara, N. 1989. Vascular endothelial growth factor is a secreted angiogenic mitogen. Science. 246:1306-1309.

6. Folkman, J. 1995. Angiogenesis in cancer, vascular, rheumatoid and other disease. Nat. Med. 1:27-31.

7. Ferrara, N., and Davis-Smyth, T. 1997. The biology of vascular endothelial growth factor. Endocr. Rev. 18:4-25

8. Gerber, H.P., Dixit, V., and Ferrara, N. 1998. Vascular endothelial growth factor induces expression of the antiapoptotic proteins Bcl-2 and A1 in vascular endothelial cells. J. Biol. Chem. 273:13313-13316.

9. Melder, R.J., et al. 1996. During angiogenesis, vascular endothelial growth factor and basic fibroblast growth factor regulate natural killer cell adhesion to tumor endothelium. Nat. Med. 2:992-997.

10. Kim, I., et al. 2001. Vascular endothelial growth factor expression of intercellular adhesion molecule 1 (ICAM-1), vascular cell adhesion molecule 1 (VCAM-1), and E-selectin through nuclear factor- $\mathrm{\kappa B}$ activation in endothelial cells. J. Biol. Chem. 276:7614-7620.

11. Barleon, B., et al. 1996. Migration of human monocytes in response to vascular endothelial growth factor (VEGF) is mediated via the VEGF receptor flt-1. Blood. 87:3336-3343.

12. Melter, M., et al. 2000. Ligation of CD40 induces the expression of vascular endothelial growth factor by endothelial cells and monocytes and promotes angiogenesis in vivo. Blood. 96:3801-3808.

13. Freeman, M.R., et al. 1995. Peripheral blood T lymphocytes and lymphocytes infiltrating human cancers express vascular endothelial growth factor: a potential role for T cells in angiogenesis. Cancer Res 55:4140-4145.

14. Soker, S., Fidder, H., Neufeld, G., and Klagsbrun, M. 1996. Characterization of novel vascular endothelial growth factor (VEGF) receptors on tumor cells that bind VEGF165 via its exon 7-encoded domain. J. Biol. Chem. 271:5761-5767. 
15. Clauss, M., et al. 1996. The vascular endothelial growth factor receptor Flt-1 mediates biological activities. Implications for a functional role of placenta growth factor in monocyte activation and chemotaxis. J. Biol. Chem. 271:17629-17634.

16. Shweiki, D., Itin, A., Soffer, D., and Keshet, E. 1992. Vascular endothelial growth factor induced by hypoxia may mediate hypoxia-initiated angiogenesis. Nature. 359:843-845.

17. Sato, K., et al. 1995. Stimulation by thyroid-stimulating hormone and Grave's immunoglobulin G of vascular endothelial growth factor mRNA expression in human thyroid follicles in vitro and flt mRNA expression in the rat thyroid in vivo. J. Clin. Invest. 96:1295-1302.

18. Shweiki, D., Neeman, M., Itin, A., and Keshet, E. 1995. Induction of vascular endothelial growth factor expression by hypoxia and by glucose deficiency in multicell spheroids: implications for tumor angiogenesis. Proc. Natl. Acad. Sci. U. S. A. 92:768-772.

19. Williams, B., Baker, A.Q., Gallacher, B., and Lodwick, D. 1995. Angiotensin II increases vascular permeability factor gene expression by human vascular smooth muscle cells. Hypertension. 25:913-917.

20. Williams, B., Quinn-Baker, A., and Gallacher, B. 1995. Serum and platelet-derived growth factor-induced expression of vascular permeability factor mRNA by human vascular smooth muscle cells in vitro. Clin. Sci. 88:141-147.

21. Reinders, M.E., Sho, M., Robertson, S.W., Geehan, C.S., and Briscoe, D.M. 2003. Proangiogenic function of CD40 ligand-CD40 interactions. J. Immunol. 171:1534-1541.

22. Reinders, M.E.J., Fang, J.C., Wong, W., Ganz, P., and Briscoe, D.M. 2003. Expression patterns of vascular endothelial growth factor in human cardiac allografts: association with rejection. Transplantation. 76:224-230

23. Shahbazi, M., et al. 2002. Vascular endothelial growth factor gene polymorphisms are associated with acute renal allograft rejection. J. Am. Soc. Nephrol. 13:260-264.

24. Pilmore, H.L., Eris, J.M., Painter, D.M., Bishop, G.A., and McCaughan, G.W. 1999. Vascular endothelial growth factor expression in human chronic renal allograft rejection. Transplantation. 67:929-933.

25. Torry, R.J., Labarrere, C.A., Torry, D.S., Holt, V.J., and Faulk, W.P. 1995. Vascular endothelial growth factor expression in transplanted human hearts. Transplantation. 60:1451-1457.

26. Kim, K.J., et al. 1993. Inhibition of vascular endothelial growth factorinduced angiogenesis suppresses tumour growth in vivo. Nature. 362:841-844.

27. Presta, L.G., et al. 1997. Humanization of an anti-vascular endothelial growth factor monoclonal antibody for the therapy of solid tumors and other disorders. Cancer. Res. 57:4593-4599.

28. Khan, I.A., et al. 2000. IP-10 is critical for effector T cell trafficking and host survival in Toxoplasma gondii infection. Immunity. 12:483-494.

29. O'Reilly, M.S., et al. 1997. Endostatin: an endogenous inhibitor of angiogenesis and tumor growth. Cell. 88:277-285.

30. Boehm, T., Folkman, J., Browder, T., and O'Reilly, M.S. 1997. Antiangiogenic therapy of experimental cancer does not induce acquired drug resistance. Nature. 390:404-407.

31. Bergers, G., Javaherian, K., Lo, K.M., Folkman, J., and Hanahan, D. 1999. Effects of angiogenesis inhibitors on multistage carcinogenesis in mice. Science. 284:808-812.

32. Tilton, R.G., et al. 1997. Vascular dysfunction induced by elevated glucose levels in rats is mediated by vascular endothelial growth factor. J. Clin. Invest. 99:2192-2202.

33. Basu, S., et al. 2001. The neurotransmitter dopamine inhibits angiogenesis induced by vascular permeability factor/vascular endothelial growth factor. Nat. Med. 7:569-574

34. Walter, D.H., et al. 1996. The in vivo bioactivity of vascular endothelial growth factor/vascular permeability factor is independent of $\mathrm{N}$-linked glycosylation. Lab. Invest. 74:546-556.

35. Dufour, J.H., et al. 2002. IFN- $\gamma$-inducible protein 10 (IP-10; CXCL10)deficient mice reveal a role for IP-10 in effector $\mathrm{T}$ cell generation and trafficking. J. Immunol. 168:3195-3204.
36. Briscoe, D.M., et al. 1999. The allogeneic response to cultured human skin equivalent in the hu-PBL-SCID mouse model of skin rejection. Transplantation. 67:1590-1599.

37. Corry, R.J., Winn, H.J., and Russell, P.S. 1973. Primarily vascularized allografts of hearts in mice. The role of $\mathrm{H}-2 \mathrm{D}, \mathrm{H}-2 \mathrm{~K}$, and non- $\mathrm{H}-2$ antigens in rejection. Transplantation. 16:343-350.

38. Lu, J., et al. 2000. Vascular endothelial growth factor expression and regulation of murine collagen-induced arthritis. J. Immunol. 164:5922-5927.

39. Hancock, W.W., et al. 2001. Donor-derived IP-10 initiates development of acute allograft rejection. J. Exp. Med. 193:975-980.

40. Yamada, A., et al. 2001. CD28-independent costimulation of T cells in alloimmune responses. J. Immunol. 167:140-146.

41. Gimbrone, M.A. 1976. Culture of vascular endothelium. Prog. Hemost. Thromb. 3:1-28.

42. Marelli-Berg, F.M., Peek, E., Lidington, E.A., Stauss, H.J., and Lechler, R.I. 2000. Isolation of endothelial cells from murine tissue. J. Immunol. Meth. 244:205-215.

43. Denton, M.D., Geehan, C., Alexander, S.I., Sayegh, M.H., and Briscoe, D.M. 1999. Endothelial cells modify the costimulatory capacity of transmigrating leukocytes and promote CD28-mediated CD4+ T cell alloactivation. J. Exp. Med. 190:555-566.

44. Murray, A.G., et al. 1994. Human T-cell-mediated destruction of allogeneic dermal microvessels in a severe combined immunodeficient mouse. Proc. Natl. Acad. Sci. U. S. A. 91:9146-9150.

45. Luster, A.D., Jhanwar, S.C., Chaganti, R.S., Kersey, J.H., and Ravetch, J.V. 1987. Interferon-inducible gene maps to a chromosomal band associated with a $(4 ; 11)$ translocation in acute leukemia cells. Proc. Natl. Acad. Sci. U. S. A. 84:2868-2871.

46. Farber, J.M. 1990. A macrophage mRNA selectively induced by $\gamma$-interferon encodes a member of the platelet factor 4 family of cytokines. Proc. Natl. Acad. Sci. U. S. A. 87:5238-5242.

47. Briscoe, D.M., and Sayegh, M.H. 2002. A rendezvous before rejection: where do T cells meet transplant antigens? Nat. Med. 8:220-222.

48. Briscoe, D.M., et al. 1995. Predictive value of inducible endothelial cell adhesion molecule expression for acute rejection of human cardiac allografts. Transplantation. 59:204-211.

49. Hancock, W.W. 2002. Chemokines and transplant immunobiology J. Am. Soc. Nephrol. 13:821-824.

50. Melter, M., Exeni, A., and Briscoe, D.M. 2002. Chemokines and their receptors in human clinical solid organ transplantation. Curr. Opin. Organ Transplant. 7:77-84.

51. Winn, R., Vedder, N., Ramamoorthy, C., Sharar, S., and Harlan, J. 1998. Endothelial and leukocyte adhesion molecules in inflammation and disease. Blood Coagul. Fibrinolysis. 9:S17-S23.

52. Denton, M.D., et al. 2000. The role of the graft endothelium in transplant rejection: evidence that endothelial activation may serve as a clinical marker for the development of chronic rejection. Pediatr. Transplant. 4:252-260.

53. Marumo, T., Schini-Kerth, V.B., and Busse, R. 1999. Vascular endothelial growth factor activates nuclear factor- $\mathrm{\kappa B}$ and induces monocyte chemoattractant protein-1 in bovine retinal endothelial cells. Diabetes. 48:1131-1137.

54. Lee, T.H., Avraham, H., Lee, S.H., and Avraham, S. 2002. Vascular endothelial growth factor modulates neutrophil transendothelial migration via up-regulation of interleukin- 8 in human brain microvascular endothelial cells. J. Biol. Chem. 277:10445-10451.

55. Hancock, W.W., et al. 2000. Requirement of the chemokine receptor CXCR3 for acute allograft rejection. J. Exp. Med. 192:1515-1520.

56. Denton, M.D., et al. 1998. Central role for CD40/CD40 ligand (CD154) interactions in transplant rejection. Pediatr. Transplant. 2:6-15.

57. Sayegh, M.H. 1999. Why do we reject a graft? Role of indirect allorecognition in graft rejection. Kidney Int. 56:1967-1979.

58. Gjertson, D.W. 2000. Impact of delayed graft function and acute rejec tion on kidney graft survival. Clin. Transpl. 467-480. 